\title{
Prevalence of primary dysmenorrhea and its effect on the quality of life amongst female medical students at King Saud University, Riyadh, Saudi Arabia
}

\author{
A cross-sectional study
}

Refan T. Hashim, Medical Student, Sara S. Alkhalifah, Medical Student, Alanoud A. Alsalman, Medical Student, Demah M. Alfaris, Medical Student, Munira A. Alhussaini, Medical Student, Raghda S. Qasim, Medical Student, Shaffi A. Shaik, PhD.

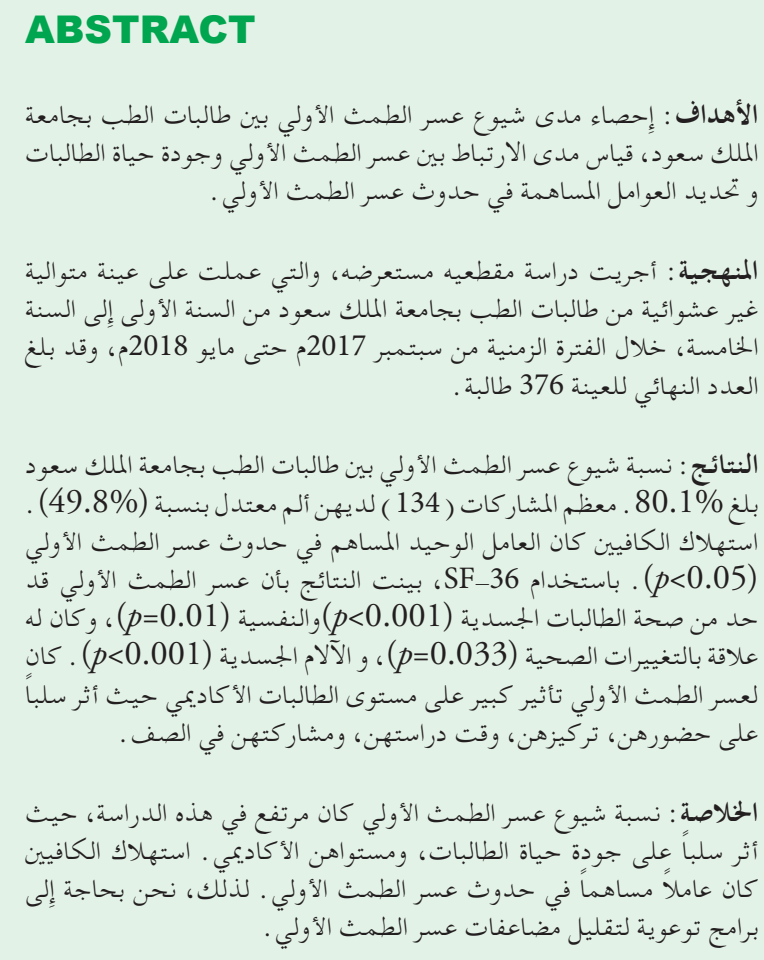

Objectives: To quantify the prevalence of primary dysmenorrhea, study its associated factors, and to assess its effect on the quality of life of female medical students.

Methods: A cross-sectional study was conducted among 376 female medical students at King Saud University student campus and King Khalid University Hospital (KKUH), Riyadh, Saudi Arabia, between September 2017 and May 2018. The study was conducted using a consecutive, non-random sampling technique.

Results: The prevalence of primary dysmenorrhea among female medical students was $80.1 \%$; most of the participants ( $\mathrm{n}=134)$ reported moderate pain (49.8\%). Primary dysmenorrhea was significantly associated with caffeine consumption $(p<0.05)$ and did not show an association with factors, body mass index, diet, lack of physical activity, and smoking. Among the SF-36 domains, the 4 domains physical health $(p<0.001)$ and emotional health $(p=0.01)$ including health changes $(p=0.033)$ and pain $(p<0.001)$ were statistically significantly affected by dysmenorrhea. Primary dysmenorrhea also had a significant impact on the students' academic performance where a higher proportion of students suffering from primary dysmenorrhea showed negative effects on their attendance, concentration, study time, and participation in class.

Conclusion: Most female medical students suffer from primary dysmenorrhea, which adversely affects their quality of life and academic performance. Caffeine consumption demonstrated a significant association with primary dysmenorrhea. Periodical awareness programs to minimize the consequences of primary dysmenorrhea should be introduced.

Keywords: dysmenorrhea, medical students, Saudi Arabia, academic performance, quality of life

$$
\text { Saudi Med J 2020; Vol. } 41 \text { (3): 283-289 }
$$$$
\text { doi: 10.15537/smj.2020.3.24988 }
$$

From the College of Medicine (Hashim, Alkhalifah, Alsalman, Alfaris, Alhussaini, Qasim), and from the Department of Family and Community Medicine (Shaik), King Saud University, Riyadh, Kingdom of Saudi Arabia.

Received 9th August 2019. Accepted 3rd February 2020.

Address correspondence and reprint request to: Prof. Shaffi A. Shaik, Prince Sattam Chair for Epidemiology and Public Health Research, Department of Family \& Community Medicine, College of Medicine, King Khalid University Hospital, King Saud University, Riyadh, Kingdom of Saudi Arabia. E-mail: sshaik@ksu.edu.sa ORCID ID: https://orcid.org/0000-0001-9900-5116 
$\mathrm{D}$ ysmenorrhea is defined as painful menstrual cramps of uterine origin. It is commonly divided into primary dysmenorrhea (pain without organic pathology) and secondary dysmenorrhea (pelvic pain associated with an identifiable pathological condition, such as endometriosis or ovarian cysts). ${ }^{1}$ It is known with certainty that primary dysmenorrhea affects millions of women worldwide. Recent local studies revealed that dysmenorrhea is a common problem among more than two-thirds of Saudi females., ${ }^{2,3}$ As for medical students in our region, dysmenorrhea was found to be prevalent among $60 \%$ and $92 \%$ of nursing students. ${ }^{4,5}$ It is a problem of great significance, not only to the affected individuals but to society as a whole by affecting women's functional abilities. ${ }^{6}$ However, it is not yet known how exactly dysmenorrhea affects students' quality of life across different aspects, such as their level of activity, emotional health, energy level, and social life.

Maintaining the same level of adequate academic performance throughout menstruation is a challenge for students. Several studies reported a decrease in students' attendance and concentration due to dysmenorrhea. ${ }^{4,7-9}$ Moreover, multiple factors are known to be related to dysmenorrhea, including the following: smoking, diet, lack of physical activity, body mass index (BMI), caffeine consumption, and so on. ${ }^{4,10}$ However, it is not currently known which of these factors has the greatest impact on dysmenorrhea in women.

This study aims to quantify the prevalence of primary dysmenorrhea and to observe the factors related to dysmenorrhea in female medical students at King Saud University, Riyadh, Saudi Arabia. Also, to evaluate its effects on the quality of life, so that students become aware of the magnitude of the problem and can make the necessary changes to improve their quality of life

Methods. This cross-sectional study was conducted between September 2017 and May 2018 at the College of Medicine, King Saud University female campus, and the KKUH female academic center, Riyadh, Saudi Arabia. Both sites of the study included a total of 692 female students. Riyadh is the capital city of the Kingdom of Saudi Arabia.

Assuming a prevalence of $50 \%$ of dysmenorrhea, with a precision of $\pm 5 \%$, and at 0.05 level of significance,

Disclosure. This study was funded by the Deanship of Science Research, through Vice Deanship of Scientific Research Chairs, King Saud University, Riyadh, Kingdom of Saudi Arabia. the study requires 384 subjects. Anticipating 50\% non-response due to electronic survey, the sample size was increased by 192, with a total target sample size of 576. To compensate for the exclusion of subjects due to clinical criteria, all female students were approached to participate in the study; as a result, a consecutive non-random sampling technique was used. Students who reported the use of oral contraceptive pills and those with gynecological/pelvic pathologies were excluded. This exclusion was due to the fact that our focus in this study is primary dysmenorrhea.

Development of study questionnaire and using SF-36 scale. The authors have developed a data collection form which includes: sociodemographics, medical and medication history, the status of dysmenorrhea, (whether it is present or absent), and the severity of the pain (mild/moderate/severe). The form also included factors contributing to dysmenorrhea such as, smoking, BMI, diagnosed psychological disorders, diet, exercise, and consumption of caffeine. Participants were also asked about their academic performance: attendance, concentration, study time, and participation. This data collection form was developed to meet the objectives of the study and by reviewing the articles on this topic.9,11 In addition, the English version of the SF-36 instrument was used. Its domains include physical functioning, role limitations due to emotional health, role limitations due to physical health, energy fatigue, emotional well-being, social functioning, pain, general health, and health changes. ${ }^{12}$ The SF-36 scale is a validated questionnaire which is widely used for measuring Health related quality of Life (HRQoL). Scores range 0 to 100 for each domain was used to quantity the HRQoL. A pilot study was carried out on 10 female students to observe the clarity of variables and its responses. A consent form was attached to the questionnaire.

Data was collected using self-administered questionnaire (which takes 10 to 20 minutes to complete) after obtaining consent to participate in the study. The study questionnaire was sent to all the female students electronically to their e-mail addresses. Those who did not respond but provided consent to participate, were approached personally to collect the data.

Statistical analysis. The statistical analysis was performed by Statistical Package for Social Sciences, for Windows version 21.0 (IBMCorp, Armonk, NY, USA). Descriptive statistics (mean, standard deviation, frequencies, and percentages) were used to describe the quantitative and categorical variables. Pearson's Chi-square test was used to test the association and to compare the proportion of categorical study variables 
in relation to dysmenorrhea (yes/no). Odds ratios were calculated to measure the association between study variables and dysmenorrhea. Binary multiple logistic regression was used to find the independent factors associated with dysmenorrhea. Non-parametric statistical test, Mann-Whitney U-test was used to compare the mean ranks of scores of domains of SF-36. A $p$-value of $<0.05$ and $95 \%$ confidence intervals (CI) were also used to report the statistical significance and precision of the results.

International Review Board approval from College of Medicine (Ref no: CMED305F1 [2017-2018]) was obtained. Voluntary participation was insured by requiring all participants providing informed consent. The consent form was clear, indicating the purpose of the study and the right of the participants to withdraw at any time without any obligation toward the study team. Participants' anonymity was insured by assigning each participant a code number for the purpose of analysis only. No incentives or rewards were provided to participants. There was no conflict of interest to be reported.

Results. Sociodemographic and menstrual history. A total of 376 students responded and completed the survey questionnaire, out of which 40 students' responses were not considered for the analysis due to use of OCP $(\mathrm{n}=10)$, and gynecological/pelvic pathologies $(\mathrm{n}=30)$. In this study, 336 student's responses were analyzed. The mean age was $20.97 \pm 1.49$ years with a range of $19-26$ years. Baseline characteristics are shown in Table 1.

Most respondent's were from first year $(26 \%)$ and third year (25\%). The majority (99\%) were single, in comparison to those who were married $(1 \%)$ or divorced (0.3\%). A family income of more than 20,000 riyals per month was reported by $17.1 \%(n=239)$ of the students, while only a small number $(1 \%)$ reported an income of less than 5000 per month. In this study, menstrual characteristics were also assessed; most students (82\%) had regular menstruation, with $78 \%$ menstruating for 3-7 days each month. Moreover, up to $81 \%$ of respondents reported moderate heaviness, assessed by the use of 3-5 pads per day. Furthermore, $61 \%$ of research participants reported a positive family history of primary dysmenorrhea. The prevalence of primary dysmenorrhea among female medical students was $80.1 \%(n=269)$, half of which $(n=134)$ reported moderate pain at $50 \%$. However, 73 participants $(27 \%)$ reported severe pain and only $62(23 \%)$ reported mild pain.

Factors associated with dysmenorrhea. The distribution of study variables in relation to
Table 1 - Distribution of socio-demographic variables and menstrual/gynecological history of study subjects $(\mathrm{N}=336)$.

\begin{tabular}{|c|c|}
\hline Variables & n $\quad(\%)$ \\
\hline Age in years $($ mean $\pm S D)$ & $20.9 \pm 1.5$ \\
\hline \multicolumn{2}{|l|}{ Year of study } \\
\hline $1^{\mathrm{st}}$ & $86(25.6)$ \\
\hline $2^{\text {nd }}$ & $72(21.4)$ \\
\hline $3^{\text {rd }}$ & $84(25.0)$ \\
\hline $4^{\text {th }}$ & $44(13.1)$ \\
\hline $5^{\text {th }}$ & $50(14.9)$ \\
\hline \multicolumn{2}{|l|}{ Marital status } \\
\hline Single & $332(98.8)$ \\
\hline Married & $3 \quad(0.9)$ \\
\hline Divorced & $1 \quad(0.3)$ \\
\hline \multicolumn{2}{|l|}{ Family income (in Saudi Riyals) } \\
\hline$<5000$ & $4 \quad(1.2)$ \\
\hline $5000-10000$ & $17 \quad(5.1)$ \\
\hline $10000-20000$ & $76(22.6)$ \\
\hline$>20000$ & $239(71.1)$ \\
\hline \multicolumn{2}{|l|}{ Menstruation duration } \\
\hline$<3$ days & $3(0.9)$ \\
\hline 3-7 days & $263(78.3)$ \\
\hline$>7$ days & $70(20.8)$ \\
\hline \multicolumn{2}{|l|}{ Pads used } \\
\hline$\leq 2$ pads/day (mild) & $38(11.3)$ \\
\hline 3 to 5 pads/day (moderate) & $272(81.0)$ \\
\hline$\geq 6$ pads/day (heavy) & $26(7.7)$ \\
\hline \multicolumn{2}{|l|}{ Regularity of menstrual cycle } \\
\hline Regular & $276(82.1)$ \\
\hline Irregular & $60(17.9)$ \\
\hline \multicolumn{2}{|l|}{ Use of other medications } \\
\hline Yes & $62(18.5)$ \\
\hline No & $274(81.5)$ \\
\hline \multicolumn{2}{|l|}{ Family history } \\
\hline Yes & $206(61.3)$ \\
\hline No & $130(38.7)$ \\
\hline
\end{tabular}

dysmenorrhea has indicated the statistically significant association with the "caffeine consumption". That is those who consume caffeine (84\%) had dysmenorrhea when compared to those who did not consume caffeine (72\%). Thus higher prevalence of dysmenorrhea was observed among caffeine consumers. Also, the odds ratio of 2.06 shows a highly statistically significant association 
Table 2 - The study variable associated with dysmenorrhea (N=336).

\begin{tabular}{|c|c|c|c|c|c|}
\hline \multirow[t]{2}{*}{ Variables } & \multicolumn{2}{|c|}{ Dysmenorrhea } & \multirow{2}{*}{$\begin{array}{l}\text { Total } \\
\text { n }(\%)\end{array}$} & \multirow[t]{2}{*}{$P$-value } & \multirow[t]{2}{*}{ Odds ratio $(95 \% \mathrm{CI})$} \\
\hline & Yes $(n=269)$ & No $(n=67)$ & & & \\
\hline \multicolumn{6}{|l|}{ Body mass index } \\
\hline$<18.5$ & $33(80.5)$ & $8(19.5)$ & $41(12.2)$ & 0.987 & $1.06(0.45,2.45)$ \\
\hline $18.5-24.9$ & $168(79.6)$ & $43(20.4)$ & $211(62.8)$ & & 1.0 (ref.) \\
\hline $25-29.9$ & $49(81.7)$ & $11(18.3)$ & $60(17.9)$ & & $1.14(0.55,2.38)$ \\
\hline$\geq 30$ & $19(79.2)$ & $5(20.8)$ & $24 \quad(7.1)$ & & $0.97(0.34,2.75)$ \\
\hline \multicolumn{6}{|l|}{ Stress level } \\
\hline Usually & $75(76.5)$ & $23(23.5)$ & $98(29.2)$ & 0.271 & $0.93(0.18,4.80)$ \\
\hline Often & $103(85.8)$ & $17(14.2)$ & $120(35.7)$ & & $1.73(0.33,9.04)$ \\
\hline Occasionally & $84(77.1)$ & $25(22.9)$ & $109(32.4)$ & & $0.96(01.19,4.92)$ \\
\hline Hardly ever & $7(77.8)$ & $2(22.2)$ & $9(2.7)$ & & 1.0 (ref.) \\
\hline \multicolumn{6}{|l|}{ Smoking } \\
\hline Yes & $4(66.7)$ & $2(33.3)$ & $6(1.7)$ & 0.407 & $0.49(0.09,2.74)$ \\
\hline No & $265(80.3)$ & $65(19.7)$ & $330(98.2)$ & & 1.0 (ref.) \\
\hline \multicolumn{6}{|c|}{$\begin{array}{l}\text { Consumption of fruits/ } \\
\text { vegetables }\end{array}$} \\
\hline Yes & $102(80.3)$ & $25(19.7)$ & $127(37.8)$ & 0.927 & 1.0 (ref.) \\
\hline No & $167(79.9)$ & $42(20.1)$ & $209(62.2)$ & & $0.97(0.56,1.69)$ \\
\hline \multicolumn{6}{|c|}{$\begin{array}{l}\text { Consumption of caffeine } \\
(n=282)\end{array}$} \\
\hline Yes & $139(83.9)$ & $37(16.1)$ & $176(62.4)$ & $0.009^{*}$ & $2.06(1.19,3.57)$ \\
\hline No & $76(71.7)$ & $30(28.3)$ & $106(37.6)$ & & 1.0 (ref.) \\
\hline \multicolumn{6}{|l|}{ Exercise/week } \\
\hline 0 & $134(79.3)$ & $35(20.7)$ & $35(20.7)$ & 0.929 & $0.87(0.40,1.90)$ \\
\hline $1-2$ & $91(80.5)$ & $22(19.5)$ & $22(19.5)$ & & $0.94(0.41,2.15)$ \\
\hline$\geq 3$ & $44(81.5)$ & $10(18.5)$ & $10(18.5)$ & & 1.0 (ref.) \\
\hline \multicolumn{6}{|l|}{ Sleep hours/day } \\
\hline$\leq 4$ & $13(68.4)$ & $6(31.6)$ & $19 \quad(5.6)$ & & $0.53(0.18,1.61)$ \\
\hline $5-7$ & $187(81.0)$ & $44(19.0)$ & $231(68.8)$ & 0.421 & $1.05(0.56,1.95)$ \\
\hline$>7$ & $69(80.2)$ & $17(19.8)$ & $86(25.6)$ & & 1.0 (ref.) \\
\hline
\end{tabular}

Data are presented as numbers and percentage (\%). *Statistically significant

between caffeine consumption and dysmenorrhea. The other study variables (BMI, stress level, smoking, consumption of fruits/vegetables, exercise/week and sleep hours/day) were not significantly associated with dysmenorrhea (Table 2).

Multivariate analysis also shows caffeine consumption as associated factor of primary dysmenorrhea with an adjusted odds ratio of 2.19 (95\% CI: 1.24, 3.89) $(p=0.007)$. Other variables stress, smoking and sleep hours/day in the model were not significantly associated with primary dysmenorrhea (Table 3).

Quality of life. The comparison of mean rank values of domains of SF-36 between the students who had dysmenorrhea and who did not have dysmenorrhea shows a statistically significant difference in the mean rank values of 4 domains (role limitation due to physical health, role limitation due to emotional health, pain and health changes). The mean rank values of these 4 domains are significantly lower in students who had dysmenorrhea when compared with the students who did not have dysmenorrhea. This finding clearly indicates that dysmenorrhea has a negative effect on some of the domains of quality of life. Other domains mean rank values did not show a statistically significant difference in relation to the presence or absence of dysmenorrhea (Table 4).

Female medical students who suffered from primary dysmenorrhea reported a negative impact on their attendance, with more than half of the sample (67\%) reporting an increase in their absenteeism. A high percentage of these students also reported a decrease in their study time (94\%), participation (86\%), and concentration (89\%). A highly statistically significant difference was observed between the subjects who had 
Table 3 - Independent factors associated with dysmenorrhea (using binary logistic regression*)

\begin{tabular}{|c|c|}
\hline Variables & Adjusted odds ratio $(95 \% \mathrm{CI})$ \\
\hline \multicolumn{2}{|l|}{ Stress level } \\
\hline Usually & $0.84(0.16,4.49)$ \\
\hline Often & $0.96(0.18,5.04)$ \\
\hline Occasionally & $1.64(0.31,8.80)$ \\
\hline Hardly ever & 1.0 (ref.) \\
\hline \multicolumn{2}{|l|}{ Smoking } \\
\hline Yes & $0.48(0.07,3.27)$ \\
\hline No & 1.0 (ref.) \\
\hline \multicolumn{2}{|c|}{ Consumption of caffeine ( $n=282$ ) } \\
\hline Yes & $2.19(1.24,3.88)$ \\
\hline No & 1.0 (ref.) \\
\hline \multicolumn{2}{|l|}{ Sleep hours/day } \\
\hline$\leq 4$ & $0.53(0.16,1.72)$ \\
\hline $5-7$ & $0.99(0.52,1.87)$ \\
\hline$>7$ & 1.0 (ref.) \\
\hline${ }^{*}$ Variables & $\begin{array}{l}\text { ate analysis were included in the } \\
\text { del }\end{array}$ \\
\hline
\end{tabular}

dysmenorrhea and who did not had dysmenorrhea towards these 4 variables of academic performance (Table 5)

Discussion. In this study, the prevalence of primary dysmenorrhea among female medical students was $80 \%$. A similar prevalence of $71 \%, 88 \%$, and $74 \%$, were reported among Saudi females. ${ }^{2,3,13}$ It is well known that increased psychological stress is a predisposing factor for developing dysmenorrhea; therefore, the stressful lifestyle of medical students could explain the high prevalence of dysmenorrhea in our studied population. ${ }^{14,15}$ Moreover, in another Nepalese study, up to $85 \%$ of students experienced an increase in the frequency and severity of dysmenorrhea after enrolling in medical school. ${ }^{16}$ However, some studies have reported prevalence as high as $94 \%$ and others, as low as $53 \%$ or $43 \% .{ }^{17-19}$ Prevalence varies widely among different populations, which is thought to be due to social and cultural reasons, the subjective nature of

Table 4 - Comparison of mean ranks of SF-domains in relation to dysmenorrhea.

\begin{tabular}{|c|c|c|c|c|}
\hline \multirow[t]{2}{*}{ SF-36 domains } & \multicolumn{2}{|c|}{ Dysmenorrhea } & \multirow{2}{*}{$\begin{array}{l}\text { Mann- } \\
\text { Whitney } \\
\text { U-value }\end{array}$} & \multirow[t]{2}{*}{$P$-value } \\
\hline & $\begin{array}{c}\text { Yes } \\
\text { mean rank }\end{array}$ & $\begin{array}{c}\text { No } \\
\text { mean ranks }\end{array}$ & & \\
\hline Physical functioning & 104.19 & 105.42 & 4059.00 & 0.891 \\
\hline Role limitation due to physical health & 158.12 & 210.19 & 6218.00 & $<0.0001^{*}$ \\
\hline Role limitation due to emotional health & 161.92 & 194.93 & 7240.50 & $0.009^{*}$ \\
\hline Energy fatigue & 130.71 & 121.35 & 4575.50 & 0.433 \\
\hline Emotional well-being & 111.67 & 110.70 & 3465.50 & 0.932 \\
\hline Social functioning & 129.02 & 131.77 & 4690.50 & 0.817 \\
\hline Pain & 154.82 & 223.42 & 5331.00 & $<0.0001^{*}$ \\
\hline General health & 65.47 & 65.66 & 1051.50 & 0.984 \\
\hline Health changes & 162.50 & 192.60 & 7397.00 & $0.012^{*}$ \\
\hline
\end{tabular}

Table 5 - Comparison of academic performance variables in relation to dysmenorrhea ( $N=336)$.

\begin{tabular}{|c|c|c|c|c|c|}
\hline \multirow[t]{2}{*}{ Academic variables } & \multicolumn{2}{|c|}{ Dysmenorrhea } & \multirow{2}{*}{$\begin{array}{c}\text { Difference of } \\
\text { proportion }(95 \% \mathrm{CI})\end{array}$} & \multirow{2}{*}{$\begin{array}{c}\text { Chi-squared- } \\
\text { value }\end{array}$} & \multirow[t]{2}{*}{$P$-value } \\
\hline & $\begin{array}{c}\text { Yes } \\
(\mathrm{n}=269)\end{array}$ & $\begin{array}{c}\text { No } \\
(\mathbf{n}=67)\end{array}$ & & & \\
\hline Attendance (affected) & $181(67.3)$ & $9(13.4)$ & $53.9(41.8,62.9)$ & 61.25 & $<0.0001^{\star}$ \\
\hline Participation (affected) & $232(86.2)$ & $24(35.8)$ & $50.4(36.9,62.4)$ & 72.27 & $<0.0001^{\star}$ \\
\hline Concentration (affected) & $239(88.8)$ & $27(40.3)$ & $48.5(35.1,60.8)$ & 73.49 & $<0.0001^{\star}$ \\
\hline Studying time (affected) & $253(94.0)$ & $30(44.8)$ & $49.2(36.1,61.6)$ & 93.88 & $<0.0001^{\star}$ \\
\hline
\end{tabular}

Data are presented as numbers and percentage $(\%)$. ${ }^{*}$ Statistically significant 
the symptoms, and the variety of diagnostic criteria. ${ }^{20}$ In this study, the degree of pain severity was rated as mild by $23 \%$, moderate by $50 \%$, and severe by $27 \%$ of our study sample. Similarly, a study in Oman reported mild dysmenorrhea in $27 \%$ of participants, moderate in $41 \%$, and severe in $32 \% .{ }^{17}$

Epidemiological studies have shown an association between primary dysmenorrhea and several environmental factors, including cigarette smoking and a lack of physical activity. ${ }^{4}$ However, in this study, we did not find an association between cigarette use and the occurrence of primary dysmenorrhea, probably due to small number of smokers among our study (6 out of 376). In addition, this study did not show a positive association between dysmenorrhea and lack of physical activity, in contrast to an experimental study where physical activity was found to have a positive impact on primary dysmenorrhea. ${ }^{21}$

The results of our analysis showed that caffeine consumption has a statistically significant association with primary dysmenorrhea $(p<0.05)$, in line with previous studies. ${ }^{11,22}$ The mechanism through which caffeine could precipitate cramp-like pain is yet to be known for certain and further studies are warranted. One hypothesized mechanism was the vasoconstricting effect of caffeine in blood vessels. ${ }^{23}$ A study on pregnant women suggests that caffeine causes increased uterine stimulation and contraction. Uterine hypercontraction reduces blood flow and results in pain. ${ }^{24}$

This study showed no association between BMI, diet and dysmenorrhea, which contradicts other studies. ${ }^{10}$ This discrepancy may be due to the differences between the study populations. Results of the current study found that there is also no association between stress and dysmenorrhea, unlike other studies which found it to be a predictor of primary dysmenorrhea in women. ${ }^{4}$

In this study, dysmenorrhea was associated with a negative effect on the SF-36 domains, including role limitation due to physical health, role limitation due to emotional health, pain, and health changes. Findings related to role limitations due to physical health and pain were consistent with a study conducted in Western Turkey. ${ }^{11}$ However, as opposed to the previous study, dysmenorrhea had a strong influence on students' emotional health in this study, possibly because it focuses on medical students in particular. Furthermore, primary dysmenorrhea did not show an evident effect on the students' energy and physical functioning in this study. However, a major impact was found in the study conducted in Western Turkey. ${ }^{11}$

The social life of women suffering from primary dysmenorrhea appeared to be unaffected in this study, agreeing with the results of other studies using the SF-36 scale. ${ }^{11}$ The majority of female medical students in this study also reported that dysmenorrhea had a negative impact on their academic performance. More than half (67\%) reported an increase in their absenteeism due to primary dysmenorrhea; related findings of $50 \%$ and $45 \%$ were found in the literature. ${ }^{25,8}$ Furthermore, the majority of students also reported a decrease in their participation $(86 \%)$, concentration $(89 \%)$, and study time (94\%). These results align with other studies, which showed similar effects on academic performance. ${ }^{6-8,25,26}$

As this is a cross-sectional study, causal relationships could not be established. Other limitations included recall bias, because the students were asked for conditions in the past prior to the study. It is important to mention that secondary dysmenorrhea could not be excluded with certainty as the cause of dysmenorrhea, because health care professionals did not examine the medical students.

In conclusion, a majority of female medical students suffer from primary dysmenorrhea, which adversely affects their quality of life and academic performance. Caffeine consumption had a significant association with primary dysmenorrhea. Periodical awareness programs should be introduced to minimize the consequences of primary dysmenorrhea.

Acknowledgment. The authors are grateful to the Deanship of Scientific Research, King Saud University, Riyadh, Kingdom of Saudi Arabia for funding through the Vice Deanship of Scientific Research Chairs. We would like to express our gratitude to the female medical students at King Saud University, Riyadh, Saudi Arabia for their time and cooperation. We also would like to thank Scribbr (ww.scribvr.com) for English language editing.

\section{References}

1. Yasir S, Kant B, Dar MF. Frequency of dysmenorrhoea, its impact and management strategies adopted by medical students. J Ayub Med Coll Abbottabad 2014; 26: 349-352.

2. Alsaleem MA. Dysmenorrhea, associated symptoms, and management among students at King Khalid University, Saudi Arabia: An exploratory study. J Family Med Prim Care 2018; 7 : 769-677.

3. Abdel-Salam DM, Alnuman RW, Alrwuaili RM, Alrwuaili GA, Alrwuaili EM. Epidemiological aspects of dysmenorrhea among female students at Jouf University, Saudi Arabia. Middle East Fertil Soc J 2018; 23: 435-439.

4. Ibrahim NK, AlGhamdi MS, Al-Shaibani AN, AlAmri FA, Alharbi HA, Al-Jadani AK, et al. Dysmenorrhea among female medical students in King Abdulaziz University: Prevalence, Predictors and outcome. PakJ Med Sci Q2015; 31: 1312-1317.

5. Ismaile S, Al-Enezi S, Otaif W, Al-Mahadi A, Bingorban N, Barayaan N. Prevalence of menstrual pain among Saudi nursing students and its effect on sickness absenteeism. Health 2016; 8: 198-205. 
6. Chia CF, Lai JH, Cheung PK, Kwong LT, Lau FP, Leung KH, et al. Dysmenorrhoea among Hong Kong university students: prevalence, impact, and management. Hong Kong Med J 2013; 19: 222-228.

7. Aref N, Rizwan F, Abbas MM. Frequency of different menstrual disorders among female medical students at Taif Medical College. World J Med Sci 2015; 12: 109-104.

8. Ruhi D, Meenal K. Prevalence of dysmenorrhea among girl students in a medical college. PJMS 2014; 4: 49-51.

9. Akinnubi CF. Influence of dysmenorrhea and menorrhagia on academic performance among female students in Tertiary Institutions in Ondo State Nigeria. WJSS 2016; 3: 34-41.

10. Lakkawar NJ, Jayavani RL, Arthi N, Alaganandam P, Vanajakshi N. A study of menstrual disorders in medical students and its correlation with biological variables. Scholars J Appl Med Sci 2014; 2: 3165-3175.

11. Unsal A, Ayranci U, Tozun M, Arslan G, Calik E. Prevalence of dysmenorrhea and its effect on quality of life among a group of female university students. Ups J Med Sci 2010; 115: 138-145.

12. Ware Jr JE, Sherbourne CD. The MOS 36-item short-form health survey (SF-36): I. Conceptual framework and item selection. Med Care 1992; 30: 473-483.

13. Abd El-Mawgod MM, Alshaibany AS, Al-Anazi AM. Epidemiology of dysmenorrhea among secondary-school students in Northern Saudi Arabia. J Egypt Public Health Assoc 2016; 91:115-119.

14. Jaiprakash H, Myint K, Chai L, Nasir B. Prevalence of dysmenorrhea and its sequel among medical students in a Malaysian University. Br J Med Med Res 2016; 16: 1-8.

15. Vlachou E, Owens D, Lavdaniti M, Kalemikerakis J, Evagelou E, Margari N, et al. Prevalence, wellbeing, and symptoms of dysmenorrhea among university nursing students in Greece. Diseases 2019; 7: 5 .
16. Katwal PC, Karki NR, Sharma P, Tamrakar SR. Dysmenorrhea and stress among the Nepalese medical students. Kathmandu Univ Med J 2016; 14: 318-321.

17. Al-Kindi R, Al-Bulushi A. Prevalence and impact of dysmenorrhoea among Omani high school students. Sultan Qaboos Univ Med J 2011; 11: 485-491.

18. Kumar KP, Kala RC, Sushil K, Gita K. Dysmenorrhea and its association with stress among female students. IJBAMR 2017; 6: 554-558.

19. Mohamed HE, Mansour SE. The effect of dysmenorrhea on quality of life of technical secondary schools girls. Med J Cairo Univ 2013; 81: 83-90.

20. Tomás-Rodríguez MI, Palazón-Bru A, Martínez-St John DRJ, Navarro-Cremades F, Toledo-Marhuenda JV, Gil-Guillén VF. Factors associated with increased pain in primary dysmenorrhea: analysis using a multivariate ordered logistic regression model. $J$ Pediatr Adolesc Gynecol 2017; 30: 199-202.

21. Vaiyapuri A, Chandrasekar L, Radhakrishnan U, Kaja R. Home based exercise management in primary dysmenorrhea. IJHRS 2016; 5: 37-42.

22. Faramarzi M, Salmalian H. Association of psychologic and nonpsychologic factors with primary dysmenorrhea. Iranian Red Crescent Med J 2014; 16: e16307.

23. Echeverri D, Montes FR, Cabrera M, Galán A, Prieto A. Caffeine's vascular mechanisms of action. Int J Vasc Med 2010; 2010: 834060.

24. Buscicchio G, Piemontese M, Gentilucci L, Ferretti F, Tranquilli AL. The effects of maternal caffeine and chocolate intake on fetal heart rate. J Matern Fetal Neonatal Med 2012; 25: 528-530.

25. Rakhshaee Z. A cross-sectional study of primary dysmenorrhea among students at a university: prevalence, impact and of associated symptoms. Annu Res Rev Biol 2014; 4: 2815-222.

26. Bt D, Derseh BT, Afessa N, Temesgen M, Semayat YW, Kassaye $M$, et al. Prevalence of dysmenorrhea and its effects on school performance: a cross-sectional study. J Women's Health Care 2017; 6: 361. 